31 simple vaginal delivery. The indications for cesarean sections are presented in Figure 1. No statistically significant difference was found on cesarean section prevalence between both groups $(p=0.389)$.

The most common indication for cesarean section in all patients was previous cesarean procedure. $(n=12,36.36 \%)$. There were more pathological fetal cardiotocographic changes (PFCC) as an indication for cesarean section on the rheumatic diseases group ( $n=11, p 0.002)$ compared with the control group $(n=1)$. Conclusion: A higher prevalence of cesarean sections was found in women with rheumatic diseases versus women without rheumatic diseases, although this difference was not statistically significant. Studies with a higher sample size are necessary to elucidate the complications and differences between both groups. REFERENCES:

[1] Jara LJ, Cruz-Dominguez MDP, Saavedra MA. Impact of infections in autoimmune rheumatic diseases and pregnancy. Curr Opin Rheumatol. 2019;31(5):546-52

[2] Saavedra MA, Sánchez A, Bustamante R, Miranda-Hernández D, SolizAntezana J, Cruz-Domínguez $\mathrm{P}$, et al. [Maternal and fetal outcome in Mexican women with rheumatoid arthritis]. Rev Med Inst Mex Seguro Soc. 2015;53 Suppl 1:S24-9.

[3] Smeele HTW, Dolhain R. Current perspectives on fertility, pregnancy and childbirth in patients with Rheumatoid Arthritis. Semin Arthritis Rheum. 2019;49(3s):S32-s5

[4] Sugawara E, Kato M, Fujieda Y, Oku K, Bohgaki T, Yasuda S, et al. Pregnancy outcomes in women with rheumatic diseases: a real-world observational study in Japan. Lupus. 2019;28(12):1407-16.

[5] Vinet É, Bernatsky S. Outcomes in Children Born to Women with Rheumatic Diseases. Rheum Dis Clin North Am. 2017;43(2):263-73.

Table 1. Demographic charecteristics

\begin{tabular}{|c|c|c|c|c|c|c|}
\hline DISEASE & $\mathrm{N}(\%)$ & $\begin{array}{c}\text { AGE, YEARS } \\
\text { MEAN }\end{array}$ & $\begin{array}{c}\text { DURATION } \\
\text { OF } \\
\text { DISEASE, } \\
\text { YEARS } \\
\text { MEAN }\end{array}$ & $\begin{array}{l}\text { CESAREAN } \\
\text { SECTION }\end{array}$ & $\begin{array}{c}\text { SIMPLE } \\
\text { VAGINAL } \\
\text { DELIVERY }\end{array}$ & OTHERS \\
\hline $\mathrm{RA}$ & $22(39.2 \%)$ & 29.95 & 6.77 & 11 & 10 & 1 Miscarriage \\
\hline APS & $9(16.98)$ & 28.22 & 2.77 & 8 & 1 & \\
\hline DM & $\begin{array}{c}3 \\
(5.35 \%)\end{array}$ & 20 & 3.5 & 2 & 1 & \\
\hline IA & $\begin{array}{c}3 \\
(5.35 \%)\end{array}$ & 21.5 & 3 & 2 & 1 & \\
\hline SS & $4(7.14 \%)$ & 30.25 & 4.75 & 3 & 1 & \\
\hline JIA & 2 (3.57\%) & 36 & 15 & 1 & 1 & \\
\hline SLE & $13(23.21)$ & 31.83 & 5.33 & 7 & 5 & \\
\hline TOTAL & 56 & 29.64150943 & & 33 & 22 & \\
\hline
\end{tabular}

RA: Rheumatoid Arthritis, APS: Anti-phospholipid syndrome, DM: Dermatomyositis, IA: Idiopathic arthritis, SS: Sjogren syndrome, JIA: Juvenile idiopathic arthritis, SLE: Systemic Lupus Erythematosus

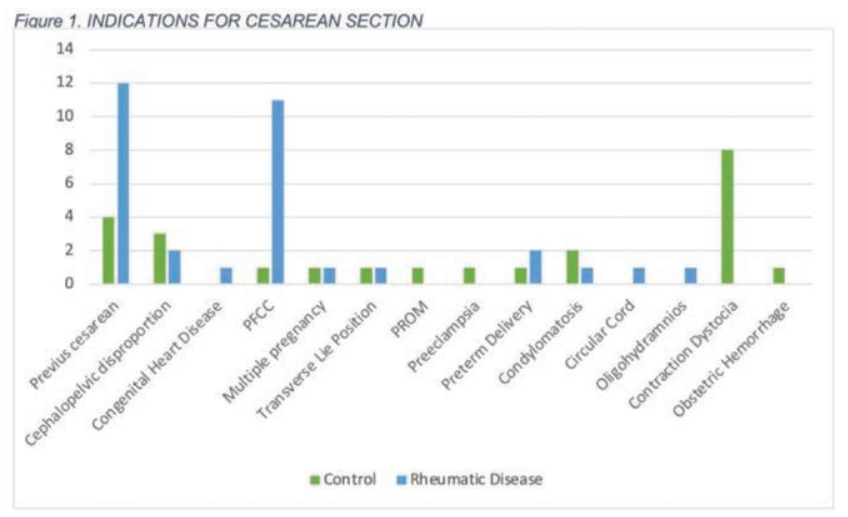

Disclosure of Interests: None declared

DOI: 10.1136/annrheumdis-2021-eular.3679

\section{AB0843 OBSTETRIC AND PERINATAL OUTCOMES IN MEXICAN WOMEN WITH RHEUMATIC DISEASES}

F. Hernández ${ }^{1}$, A. Y. Lujano Negrete ${ }^{2}$, C. M. Skinner Taylor ${ }^{2}$, L. Pérez Barbosa ${ }^{2}$, E. Barriga-Maldonado ${ }^{2}$, R. A. Rodriguez Chavez ${ }^{2}$, L. G. Espinosa Banuelos ${ }^{2}$,
R. Moyeda Martinez ${ }^{2}$, G. Figueroa-Parra ${ }^{2}$, D. Á. Galarza-Delgado ${ }^{2} .{ }^{1}$ Hospital Universitario Dr. José Eleuterio González, Obstetricia, Monterrey, Mexico; ${ }^{2}$ Hospital Universitario Dr. José Eleuterio González, Reumatología, Monterrey, Mexico

Background: Rheumatic diseases (RD) are more frequent among women of childbearing age. Adverse events during pregnancy in RDs have been frequently reported, leading some women to avoid pregnancy. "CEER" is an outpatient clinic in Monterrey, Nuevo Leon, Mexico, that was created for pregnant women with RD.

Objectives: The objective is to describe pregnancy outcomes in patients with RD surveilled at a rheumatology outpatient clinic.

Methods: A single-center retrospective study of women with RD at CEER between 2017 and 2020 was conducted. Clinical features and maternal, fetal and neonatal outcomes were retrospectively collected. The rate of adverse perinata outcomes (APO) was compared with the tertiary referral center's general obstetric population (GOP). All data was retrieved from clinical files.

Results: Overall, 62 pregnancies in women with RD were recorded. The median maternal age at conception was significantly higher in pregnancies with RD than GOP (29 [24-35] years old vs 23 [19-28] years old, $p<0.001)$. The odds of preterm delivery were increased among pregnancies with RD (OR 1.85, 95\% Cl 1.033.30, $p=0.038$ ). Other APO are summarized in Table 1. Rheumatoid arthritis (RA) was the leading diagnosis followed by systemic erythematosus lupus (SLE) and antiphospholipid syndrome (APS).

Cesarean sections were recorded in 41 pregnancies in RD group, more frequent than in GOP $(66.1 \%$ vs $50.8 \%, \mathrm{p}=0.016)$. Figure 1 shows the distribution of indications for cesarean sections, the two leading indications were previous cesarean section (43.9\%) and Nonreassuring fetal heart rate pattern $(19.5 \%)$ Pregnancies with RD appeared to have frequent, emergency cesarean sections and preterm deliveries compared with GOP (12.9\% vs $15.9 \%, \mathrm{p}=0.02$ and $23.7 \%$ vs $12.2 \%, p=0.006$, respectively).

Conclusion: Pregnancies with RD were at increased risk for APO. Women of this population should be made aware of these risks and be closely monitored by a multidisciplinary team as a high-risk pregnancy.

\section{REFERENCES:}

[1] Aljary H, Czuzoj-Shulman N, Spence AR, Abenhaim HA. Pregnancy outcomes in women with rheumatoid arthritis: a retrospective population-based cohort study. J Matern Fetal Neonatal Med. 2020;33(4):618-24.

[2] Alvarez-Nemegyei J, Cervantes-Díaz MT, Avila-Zapata F, Marín-Ordóñez J. [Pregnancy outcomes before and after the onset of rheumatoid arthritis]. Rev Med Inst Mex Seguro Soc. 2011;49(6):599-604.

[3] Davutoğlu EA, Ozel A, Yılmaz N, Madazli R. Pregnancy outcome in 162 women with rheumatic diseases: experience of a university hospital in Turkey. Arch Gynecol Obstet. 2017;296(6):1079-84

[4] Harris N, Eudy A, Clowse M. Patient-Reported Disease Activity and Adverse Pregnancy Outcomes in Systemic Lupus Erythematosus and Rheumatoid Arthritis. Arthritis Care Res (Hoboken). 2019;71(3):390-7.

[5] Ideguchi H, Ohno S, Uehara T, Ishigatsubo Y. Pregnancy outcomes in Japanese patients with SLE: retrospective review of 55 pregnancies at a university hospital. Clin Rev Allergy Immunol. 2013;44(1):57-64

Table 1. Pregnant outcome, maternal, fetal and neonatal adverse events

\begin{tabular}{|c|c|c|c|c|}
\hline & $R D(n=62)$ & GOP $(n=31254)$ & OR (Cl 95\%) & $\mathbf{p}$ \\
\hline \multicolumn{5}{|l|}{ Pregnancy outcome } \\
\hline Pregnancy loss ${ }^{\mathrm{a}}$ & $6(9.68)$ & $1560(4.99)$ & $1.94(0.84-4.49)$ & 0.122 \\
\hline Live births $^{\mathrm{a}}$ & $60(90.9)$ & $29694(95)$ & $0.96(0.67-1.35)$ & 0.8 \\
\hline Gestational age, & $37.6(37-39)$ & $39(38-40.2)$ & - & $<0.001$ \\
\hline \multicolumn{5}{|l|}{ median (IQR) (weeks) ${ }^{\mathrm{b}}$} \\
\hline Birth weight, & $\begin{array}{c}2831.6 \\
(2677.4-2985.8)\end{array}$ & $\begin{array}{c}3022.2 \\
(2986.8-3057.6)\end{array}$ & - & 0.007 \\
\hline \multicolumn{5}{|l|}{ mean $(\mathrm{Cl})(\mathrm{Kg})^{\mathrm{C}}$} \\
\hline \multicolumn{5}{|l|}{ Maternal adverse events } \\
\hline Preterm deliveries & $14(23.7)$ & $3821(12.2)$ & $1.85(1.03-3.3)$ & 0.038 \\
\hline \multicolumn{5}{|l|}{$(<37 \text { weeks })^{a}$} \\
\hline$<34$ weeks $^{\mathrm{a}}$ & $3(5.1)$ & $1065(3.4)$ & $1.42(0.45-4.53)$ & 0.553 \\
\hline Gestational diabetes $^{a}$ & $4(6.5)$ & $1406(4.5)$ & $1.43(0.52-3.95)$ & 0.485 \\
\hline Preeclampsia ${ }^{\mathrm{a}}$ & $5(8.1)$ & 2471 (7.89) & $1.02(0.41-2.54)$ & 0.97 \\
\hline Postpartum hemorrhage $^{\mathrm{a}}$ & 0 & $930(2.97)$ & $0.27(0.017-4.35)$ & 0.355 \\
\hline Emergency cesarean section ${ }^{a}$ & $8(12.9)$ & $1844(5.9)$ & $2.19(1.05-4.57)$ & 0.037 \\
\hline \multicolumn{5}{|l|}{ Fetal adverse events } \\
\hline Stillbirths ${ }^{\mathrm{a}}$ & $3(4.8)$ & $897(2.87)$ & $1.69(0.53-5.38)$ & 0.377 \\
\hline Congenital abnormalities $^{a}$ & $4(6.5)$ & $1094(3.5)$ & $1.84(0.67-5.08)$ & 0.237 \\
\hline
\end{tabular}

${ }_{\mathrm{a}}^{\mathrm{a}} \%{ }^{\mathrm{b}} \mathrm{IQR}$, interquartile range (25th-75th percentile) ${ }^{\mathrm{C}} \mathrm{Cl}$, confidence interval (95\%) 


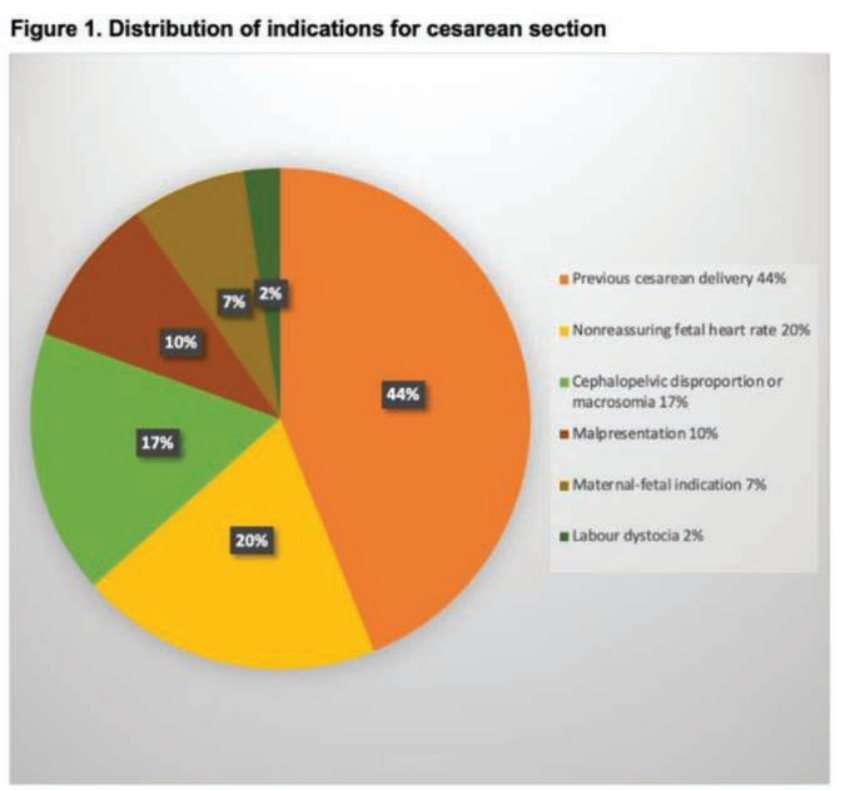

Disclosure of Interests: None declared

DOI: 10.1136/annrheumdis-2021-eular.3718

\section{AB0844 HAND GRIP STRENGTH EVALUATION IN RHEUMATOLOGIC DISEASES}

A. Caturano ${ }^{1}$, P. C. Pafundi ${ }^{1}$, R. Galiero ${ }^{1}$, M. Tardugno ${ }^{2}$, F. C. Sasso ${ }^{1}$, G. Cuomo ${ }^{2}$. 'University of Campania "Luigi Vanvitelli", Department of Advanced Medical and Surgical Sciences, Naples, Italy; ${ }^{2}$ University of Campania "Luigi Vanvitelli,' Department of Precision Medicine, Naples, Italy

Background: Handgrip muscle strength test describes the strength of the hand muscles used to grasp or grip. Currently, hand grip evaluation is often used in clinical practice, as a marker of function and disability. In fact, it has already been applied as an outcome measure in arthritis rheumatoid clinical trials, to demonstrate the benefits of several treatments [1]. However, hand disability should also be considered in all other rheumatological diseases.

Objectives: The main aim of this study is to assess the handgrip muscle strength test in a rheumatological cohort of patients as compared to a control group. Methods: This is a cross-sectional pilot study. We considered eligible 35 rheumatological consecutive female patients followed at our outpatients' clinic of Internal Medicine (I Policlinico of Naples) and 35 healthy control females (HC). Both groups included only right-handed individuals. Rheumatological patients were distributed as follows: 5 rheumatoid arthritis $(14,3 \%), 9$ psoriatic arthritis $(25,7 \%)$, 4 systemic lupus erythematosus $(11,4 \%), 10$ systemic sclerosis $(28,6 \%), 4$ fibromyalgia $(11,4 \%)$, 3 juvenile idiopathic arthritis $(8,6 \%)$. The course of disease was under optimal treatment in all patients.

The type of hand grip used is the power grip, in which an object is held firmly by wrapping the fingers around it, pressing the object against the palm, and using the thumb to apply counter-pressure. We considered as either right or left hand valid measure the mean of three consecutive tests per arm. Between-groups differences were tested both by a uni- and multivariable analysis.

Results: The two subgroups were homogeneously distributed for age (median age 42 yrs. [IQR 33-48] vs. 36 yrs. [IQR 30-52] in $\mathrm{HC} ; \mathrm{p}=0.902$ ). At univariate analysis, hand grip strength was significantly lower in the rheumatological patients, both at right hand (right $19.5 \mathrm{~kg}$ [IQR 13.6-24.8] vs. $24.5 \mathrm{~kg}$ [IQR 20.8-29] in HC; $\mathrm{p}=0.004$ ) and left hand (18.5 kg [IQR 13.9-22.5] vs. $23.7 \mathrm{~kg}$ [IQR 19-27.3] in HC; $\mathrm{p}=0.002$ ), as compared to $\mathrm{HC}$. This finding was further confirmed at multivariable analysis only as for the left hand (OR $0.919,95 \% \mathrm{Cl}: 0.858-0.984 ; \mathrm{p}=0.016$ ).

Conclusion: Rheumatological diseases are burdened by hand disability, mostly affecting daily activities performance [2,3]. Beyond an optimal disease control, our pilot study shows a decrease in left hand strength as compared to healthy controls. This might be due to a reduced use of the non-dominant hand, which may lead over time to a higher deficit of strength. As such, these patients should be prescribed to a left hand exercise to improve both mobility and strength and, consequently, hand function.

REFERENCES:

[1] Eberhardt K, Sandqvist G, Geborek P (2008) Hand function tests are important and sensitive tools for assessment of treatment response in patients with rheumatoid arthritis. Scand J Rheumatol 37(2):109-112.
[2] Feced Olmos CM, Alvarez-Calderon O, Hervás Marín D, et al. Relationship between structural damage with loss of strength and functional disability in psoriatic arthritis patients. Clin Biomech (Bristol, Avon). 2019 Aug;68:169174. doi: 10.1016/j.clinbiomech.2019.06.009.

[3] Maddali-Bongi S, Del Rosso A, Mikhaylova S, et al. Impact of hand and face disabilities on global disability and quality of life in systemic sclerosis patients. Clin Exp Rheumatol. 2014 Nov-Dec;32(6 Suppl 86):S-15-20.

Disclosure of Interests: None declared

DOI: 10.1136/annrheumdis-2021-eular.3860

\section{AB0845 THE COMBINATION OF PLASMA FIBRINOGEN CONCENTRATION AND NEUTROPHIL-LYMPHOCYTE RATIO (F-NLR) AS A NOVEL INFLAMMATORY MARKER OF RHEUMATOID ARTHRITIS}

M. Liu ${ }^{1}$, Z. Huang ${ }^{1}$, Y. Huang ${ }^{1}$, Z. Huang ${ }^{1}$, Q. Huang ${ }^{1}$, T. W. LI ${ }^{1} .{ }^{1}$ Guangdong Second Provincial General Hospital, Department of Rheumatology and Immunology, Guangzhou, China

Background: The combined index of fibrinogen and neutrophil-lymphocyte ratio (F-NLR) has recently been reported as a new predictive factor in patients with cancer. However, the fibrinogen and NLR have not been simultaneously evaluated in rheumatoid arthritis (RA).

Objectives: This study aimed to explore the clinical value of F-NLR in RA and its relationship with disease activity.

Methods: This retrospective study collected 143 RA patients and 82 age- and gender-matched healthy controls. Neutrophil, lymphocyte, monocyte, platelet, fibrinogen, NLR, monocyte to lymphocyte ratio (MLR), platelet to lymphocyte ratio (PLR), C-reactive protein (CRP), erythrocyte sedimentation rate (ESR), Disease Activity Score of 28 joints-ESR (DAS28-ESR) and other laboratory parameters were recorded. Receiver operating characteristic $(\mathrm{ROC})$ curves were used to defined the optimization cut-off values of fibrinogen and NLR, which were $3.9 \mathrm{~g} / \mathrm{L}$ and 2.42. The F-NLR score was 2 for patients with high fibrinogen $(>3.9 \mathrm{~g} / \mathrm{L})$ and elevated NLR (>2.42), while those with one or neither were indexed as 1 or 0 . The correlations between F-NLR as well as other inflammatory indexes and DAS28-ESR were measured.

Results: The F-NLR score was higher in RA patients than that in healthy individuals $(P<0.05)$. The proportion of higher F-NLR score increased significantly along with the disease activity $(P<0.05)$. According to the ROC curve which was conducted to discriminate RA patients from healthy subjects, the area under curve (AUC) of F-NLR $(0.803,95 \% \mathrm{Cl}: 0.744-0.861)$ was higher than that of fibrinogen (0.735, 95\% Cl: 0.670 - 0.801), NLR $(0.724,95 \% \mathrm{Cl}: 0.655-0.794)$ $\operatorname{MLR}(0.687,95 \% \mathrm{Cl}: 0.615-0.759)$ and PLR $(0.732,95 \% \mathrm{Cl}: 0.664-0.800)$. Furthermore, F-NLR was more strongly associated with DAS28-ESR $(r=0.572, P<$ $0.001)$ when compared with fibrinogen $(r=0.518, P<0.001)$, NLR $(r=0.365, P<$ $0.001)$, MLR $(r=0.140, P=0.096), \operatorname{PLR}(r=0.239, P=0.004)$, CRP $(r=0.539$, $P<0.001)$ and ESR $(r=0.487, P<0.001)$.

Conclusion: The results demonstrated that the F-NLR score was elevated in RA patients. The F-NLR score may be a potential marker to monitor the disease activity of RA patients.

\section{REFERENCES:}

[1] Wang H, Zhao J, Zhang M, Han L, Wang M, Xingde L. The combination of plasma fibrinogen and neutrophil lymphocyte ratio (F-NLR) is a predictive factor in patients with resectable non small cell lung cancer. J Cell Physiol. 2018 May; 233(5):4216-4224.

Disclosure of Interests: None declared

DOI: 10.1136/annrheumdis-2021-eular.3929

\section{Education}

\section{AB0846}

CONCEPTION AND FEASIBILITY OF A DIGITAL TELEGUIDED ABDOMEN, THORAX AND THYROID GLAND ULTRASOUND COURSE FOR MEDICAL STUDENTS

E. Höhne ${ }^{1}$, F. Recker ${ }^{2}$, E. Schmok ${ }^{3}$, P. Brossart ${ }^{1}$, T. Raupach ${ }^{4}$, V. Schäfer ${ }^{1}$. ${ }^{1}$ University Hospital Bonn, Clinic of Internal Medicine III, Oncology, Hematology, Rheumatology and Clinical Immunology, Bonn, Germany; ${ }^{2}$ University Hospital Bonn, Department for Obstetrics and Gynecology, Bonn, Germany; ${ }^{3}$ Amboss GmbH, Institutional Partnerships, Berlin, Germany; ${ }^{4}$ University Hospital Bonn, Institute for Medical Education, Bonn, Germany

Background: Over the past few decades, technological advances in both ultrasound (US) and the application of telemedicine have been made [1]. Medical education has shifted to online classes during the COVID-19 pandemic, creating challenges in adequate training of US. 